\title{
STRUCTURE OF THE VITREOUS BODY* OBSERVATIONS BY MEANS OF THE PHASE-CONTRAST MICROSCOPE
}

\author{
BY
}

\section{ANTONIO A. ROSSI}

From the Institute of Ophthalmology, London (Director of Research, Sir Stewart Duke-Elder) and the Ophthalmic Clinic of the University of Turin, Italy (Director, Prof. Riccardo Gallenga)

THE problem of the structure of the vitreous body has long been debated. According to Duke-Elder (1930), the argument is beset with difficulties over which anatomists have disputed from the earliest times, largely because of the difficulties involved in the interpretation of their observations. Many studies have been undertaken with the microscope on fixed specimens, with the ultramicroscope on fresh vitreous, and with the slit-lamp in the living eye. Most workers, including Baurmann (1923), Comberg (1925), Heesch (1926), Redslob and Reiss (1928), and Duke-Elder (1930), on the basis of their observations or from chemical studies, reached the conclusion that fresh vitreous body is to be considered a colloid in the form of a gel and is completely free from microscopical structures as these are usually understood.

Recently, however, the problem has again attracted interest, and several investigators whose findings do not always agree in detail, have maintained that the vitreous body has a fibrous structure. By means of the phasecontrast and electron microscope, Schwarz and Schuchardt (1950), Schwarz (1951), Bembridge, Crawford, and Pirie (1952), and Grignolo (1952), succeeded in demonstrating some fibrous elements in the fresh vitreous of several species; these varied in shape, size, and pattern according to the part of the vitreous body from which they were derived.

The present research was started with the intention of studying the vitreous in both normal and pathological conditions in animals and human beings. When the preliminary results had been obtained, however, it was thought sufficient to limit the investigation to the normal vitreous body of animals, since fresh specimens invariably failed to reveal a true fibrous structure.

\section{Method}

The technique used by Bembridge and others (1952) appeared to cause least damage to the vitreous body and was followed with minor modifications at the time of enucleation and in the method of observation under the phase-contrast microscope.

Rabbits, killed by means of an injection of nembutal into the marginal ear vein, were used for most of these experiments. Immediately after enucleation of the eye, the sclera was exposed, and after an incision about $1.5 \mathrm{~cm}$. long had been made with a razor-blade at the equator, an appropriate portion was excised either

* Received for publication January 30, 1953 
anteriorly towards the limbus with two parallel incisions or posteriorly towards the posterior pole. The choroid and the retina were then removed exposing the vitreous. A portion of the vitreous was grasped with forceps and cut off with scissors. The vitreous specimen was placed on a slide, sometimes with, sometimes without a drop of saline solution, and a coverslip was laid upon it, care being taken to exert the least possible pressure.

The specimens were then examined immediately under the phase-contrast microscope.

Other specimens of fresh vitreous were treated either just before or during the microscopic observations with various fixatives-formalin, 5 per cent, formalin and sodium chloride, acetic acid, 75 per cent (and lower concentrations), and potassium dichromate, 2.5 per cent. In a few cases specimens were fixed by gentle heating.

The animals were divided into three groups:

(a) The eyes were enucleated immediately after death and the vitreous body was studied within $15-20$ min.

(b) The eyes were enucleated immediately after death but were stored at $2^{\circ} \mathrm{C}$., the vitreous body being studied after an interval of from 2 to 8 hours.

(c) The eyes were enucleated 6 to 8 hours after death, the vitreous being studied either immediately or after 6 to 8 hours in the refrigerator.

\section{Results}

In these experiments, it was never possible to detect a true microscopic fibrous structure in the very fresh untreated samples obtained from any part of the vitreous body of animals in groups $(a)$ and $(b)$. The only formations observed were indistinct structures which with very high magnification resembled crystals of diverse appearance, outline, and grouping (Fig. 1).

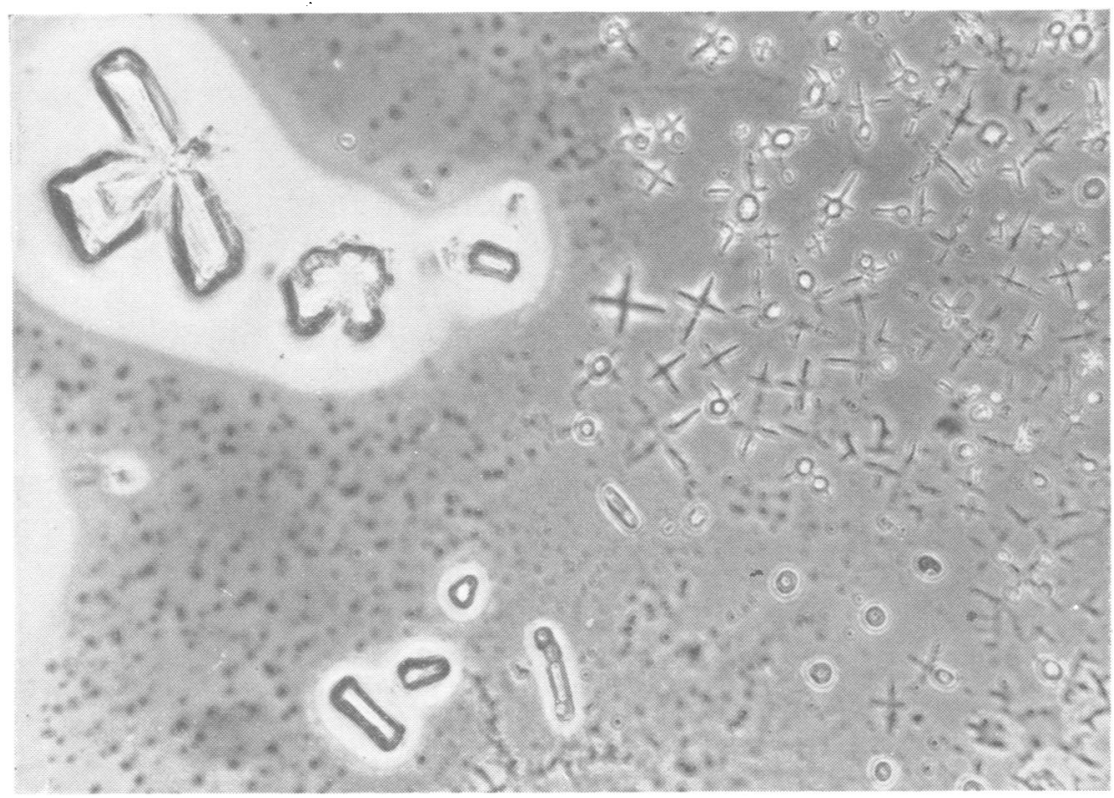

FIG. 1.-Crystal formations in very fresh rabbit vitreous. $\quad \times 320$. 


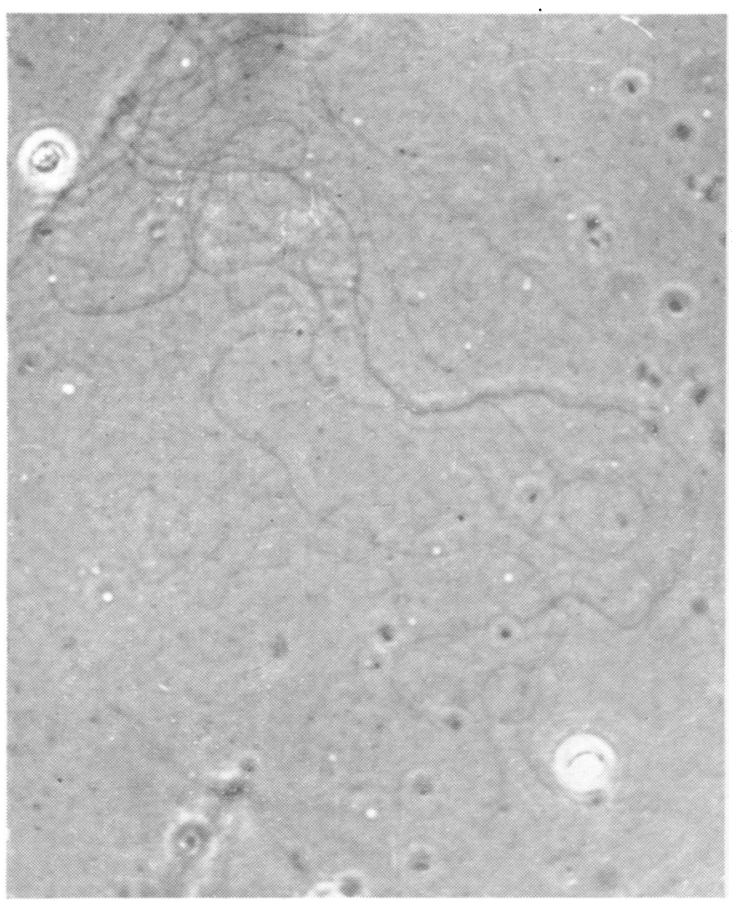

Fig. 2.-Fibrillar structures in rabbit vitreous 90 min. after exposition. $\times 330$.

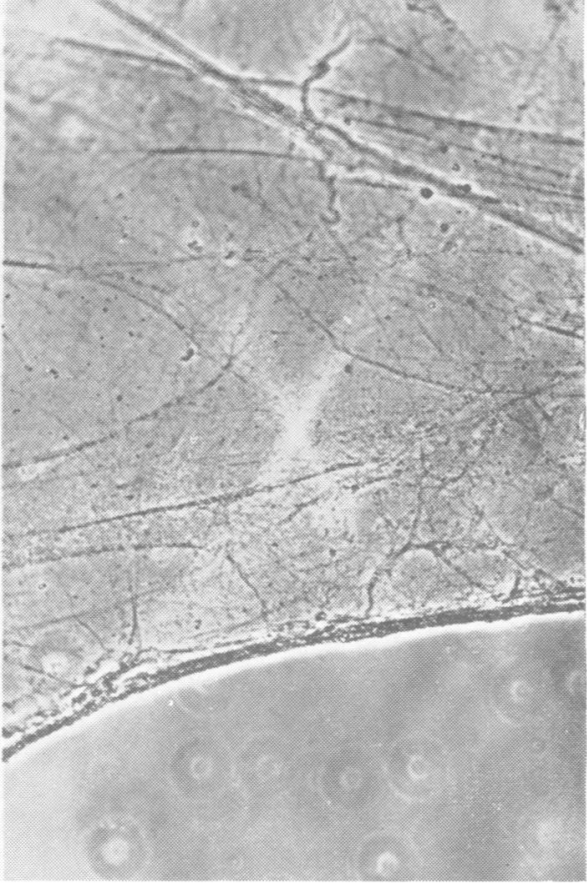

FIG. 3.-Vitreous body of rabbit treated with acetic acid. 133 .

Only 40-50 min. after the eyes had been opened did fibrillar structures commence to appear if the vitreous were exposed and its fluid allowed to drip away. These structures became more evident after 90 min. or more (Fig. 2).

The findings in the animals of group $(c)$, in which post-mortem changes had presumably taken place, are particularly interesting. In these vitreous bodies there was seen an irregular fibrillar network, which appeared in specimens collected both from in front and from behind the equator. The network was formed by fibres of various width, which ramified and anastomosed irregularly, running in more than one direction.

A microscopic fibrous structure, similar to but not identical with the picture presented by the shape-characteristics of the last group, was clearly observed in the vitreous of the animals of all three groups when the preparations were treated with any of the various fixatives (Fig. 3). There is no doubt that this was mainly due to the precipitation of the protein constituent by the fixatives, as it was possible to see the formation of the network under the microscope when a drop was placed at the edge of the coverslip.

All the above experiments were repeated many times, always with the same results.

Further observations on the vitreous body of animals and of human beings have been undertaken, and the results are to be published in another communication (Rossi, 1953). The human eyes for these experiments were 
supplied by the Eye Bank of the Ophthalmic Clinic of Turin. It is now possible to say that in human eyes a fibrous structure was detected either in $\frac{\omega}{\vec{J}}$ front of or behind the equator (Fig. 4). These results agree with the findingso in the rabbits of group $(c)$; and in this group we should reasonably include $\overrightarrow{\bar{F}}$ the human eyes as they were enucleated from 6 to $24 \mathrm{hrs}$ after death.

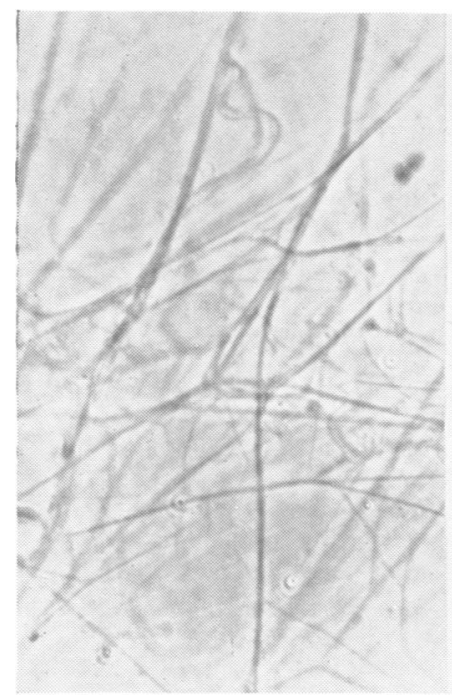

Fig. 4.-Human vitreous body from eye enucleated 22 hrs after death. $\times 800$.

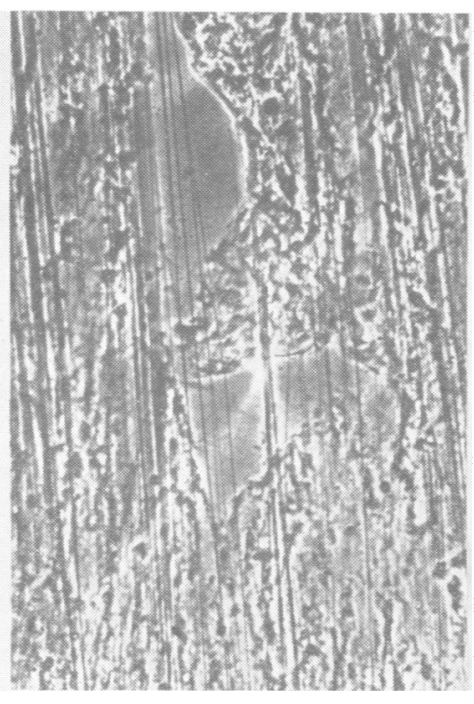

Fic. 5.-Zonular fibres and retinal fragments of the ciliary region. 85 .

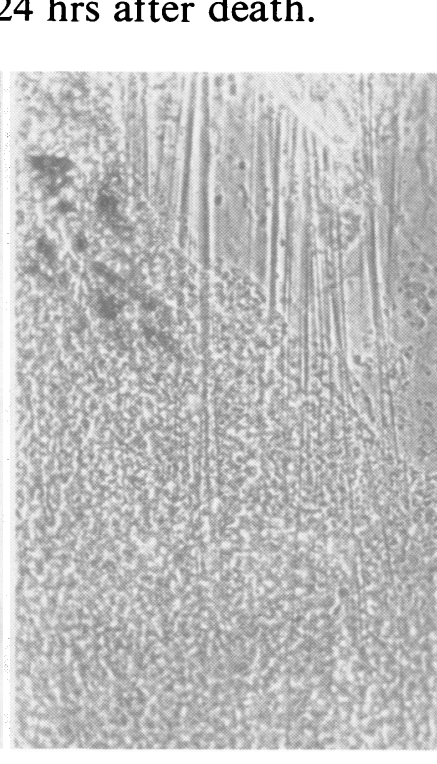

FIG. 6.-Zonular fibres very close to the ciliary body. 85 .

\section{Discussion and Conclusions}

These findings do not agree with the recent conclusions of other workers. 3 Schwarz and Schuchardt (1950) described fibres in the vitreous of the ciliary region and a fibrous network in the body of the vitreous and in specimenso collected from the fossa patellaris; Bembridge and others (1952) found $a_{\circ}^{\circ}$ different structure according to the various regions of the vitreous-a coarse 3 . branching fibrous structure in front of the equator and a very fine parallelo fibrous structure in the main body. Grignolo (1952) described branching fibres forming a network in the part posterior to the equator.

In assessing and interpreting these results, it is of the greatest importance to point out the difficulty in collecting preparations of vitreous free from other structures in the ciliary region where fibres have been detected most frequently. It would seem probable that, strictly speaking, these fibres do N not belong to the vitreous but to the zonule. It is known that the zonulare fibres originate as very thin filaments from the fusiform cells of the pars? ciliaris retinae, which covers the ciliary body as far as the ora serrata. As? they pass towards the lens, these filaments join together to form thicker anastomosing fibrillae. These fibrillae, arising from all parts of the pars ciliaris retinae form a network and join together ultimately to form the thick $\frac{\Omega}{\circ}$ zonular fibres. Both zonular structures, the thin fibrillae and the fibres, 
are completely immersed in the vitreous, so that it is impossible to separate the fibres from the gel, even by washing the specimens many times with saline solutions.

As the fibres reach the level of the crystalline lens, they anastomose no further and run straight and nearly parallel to the equator of the lens, where they spread out on the capsule. The appearance of these zonular fibres, as observed by the phase-contrast microscope (Garzino, 1953), is such that it is not surprising that they have been mistaken for branched vitreous fibres. In this connection it is interesting that coarse branching fibres have not been found in vitreous preparations taken from behind the equator or from the centre of the vitreous body (Bembridge and others, 1952). In our preparations these fibres were very obvious in specimens taken close to the ciliary region, and particularly in those in which some of the ciliary body was still present (Figs 5 and 6).

The results of the present investigation seem rather to confirm the conclusions of the many workers who have stated that the vitreous is a colloid in the form of a gel. Earlier observations that the vitreous body had a microscopic fibrous structure were regarded later as groundless; this structure was merely an experimental artefact. In preparations of very fresh vitreous, several workers have found it impossible to detect a true microscopic structure in the usual sense of the term (Cattaneo, 1930; Bruni, 1943).

According to Duke-Elder (1930):

The chemical analysis (of the vitreous body) seems to suggest very strongly that it is a gel, formed upon the basis of two special protein constituents, each with a specific function, elaborated by the surrounding ectoderm, and that the common intra-ocular fluid percolates them combining with them physically to form the gel.

The two special constituents-hyaluronic acid and residual protein-are of the greatest importance in determining the formation and appearance of these pseudo-fibrous structures. In view of the physico-chemical state of the vitreous, its chemical constitution and physical properties it can be readily assumed that these two constituents can readily undergo modifications due to variations in the $p \mathrm{H}$ or isoelectric point, in pressure or temperature, or, finally, from the loss of fluid when the vitreous is draining in vitro. By this means, the colloid micellae of amicronic dimensions (still being within the limits of the molecular world) in solution in the vitreous, can grow to submicronic dimensions and can eventually appear as fibres.

\section{Summary}

(1) Examination of very fresh vitreous body of rabbits by the phasecontrast microscope failed to detect a true fibrous structure.

(2) A fibrous structure was detected in preparations of vitreous which were not fresh and in samples treated with fixatives. 
I am particularly grateful to Sir Stewart Duke-Elder for his constant help and encouragement and for his kindness in affording me facilities to carry out this work. I thank Dr. N. Ashton for advice, Mr. J. Edwards for his technical assistance, and Dr. M. Maurice for his assistance in the writing of this paper.

\section{REFERENCES}

Baurmann, M. (1923). v. Graefes Arch. Ophthal., 111, 352.

Bembridge, B. A., Crawford, G. N. C., and Pirie, A. (1952). British Journal of Ophthalmology, 36, 131 .

Bruni, A. C. (1943). Arch. Ital. Anat. Embriol., 49, 229.

Cattaneo, D. (1930). R.C. Accad. Lincei., 12, 599.

COMBERG, W. (1924). Klin. Mbl. Augenheilk., 72, 692.

DUKe-EldER, S. (1930). British Journal of Ophthalmology, Suppl. 4, “ The Nature of the Vitreous Body". (1942). "Text-book of Ophthalmology", 2nd imp., Kimpton, London.

Garzino, A. (1953). Rass. ital. Ottal., 22 (In the press).

Grignolo, A. (1952). Arch. Ophthal., Chicago, 47, 760.

HeEsCH, K. (1926). Arch. Augenheilk., 97, 534.

Redslob, E., and ReIss, P. (1928). Ann. Oculist., Paris, 165, 641.

SCHWARZ, W. (1951). Z. Zellforsch., 36, 45. and SChUChARDT, E. (1950). Ibid., 35, 293. 